\title{
NIKETCHE: UMA PERFORMANCE LITERÁRIA DE LIBERTAÇÃO
}

\section{NIKETCHE: A LITERARY PERFORMANCE OF FREEDOM}

\author{
Renata Vaz Shimbo ${ }^{1}$
}

\section{RESUMO}

Realizamos, neste artigo, a análise do romance Niketche: uma história de poligamia, da escritora moçambicana Paulina Chiziane, com o propósito de evidenciar a subversão do ritual da dança niketche como performance literária através da subjetivação da voz feminina em Moçambique. O traçado cultural, marcado pelas diferenças geográficas do país, modela as relações que as mulheres moçambicanas estabelecem com seus corpos. Por sua vez, a língua portuguesa, elemento de dominação, cria o pano de fundo no qual a narrativa se costura. Juntos, formam o cenário evocado por Chiziane para dar palco a uma narrativa feminina que versa sobre o ato de ser mulher em Moçambique.

PALAVRAS-CHAVE: Niketche; Paulina Chiziane; literatura moçambicana.

\section{ABSTRACT}

In this article we analyze the novel Niketche: uma história de poligamia by the Mozambican writer Paulina Chiziane, with the purpose of demonstrating the subversion of the niketche dance ritual as a literary performance through the subjectivation of the female voice in Mozambique. The cultural layout, marked by the country's geographical differences, shapes the relationships that Mozambican women establish with their bodies. In turn, the Portuguese language, an element of domination, creates the background in which the narrative is sewn. Together, they form the scenario evoked by Chiziane to stage a female narrative about the act of being a woman in Mozambique.

KEYWORDS: Niketche; Paulina Chiziane; Mozambican literature. 


\section{A PLURALIDADE MOÇAMBICANA}

Niketche ${ }^{2}$ : uma história de poligamia é o quarto romance de Paulina Chiziane, publicado em 2003, e cuja narrativa abarca o reflexo e questionamento dos lugares do feminino na sociedade moçambicana, sejam eles oriundos dos costumes bantus ou que surgiram a partir do processo de colonização. O nome da obra alude a uma dança tradicional de Moçambique, executada por mulheres como rito sexual, mas que, para este estudo, seria a via de subjetivação da voz da mulher moçambicana, libertando-se através da performance literária por meio da subversão do ritual.

Chiziane nasceu em Manjacaze, em 1955, e consitui-se, hoje, como um dos maiores nomes da literatura moçambicana. A autora, alfabetizada em português por realizar seus estudos em uma escola de missão católica, envolveu-se ativamente no contexto político moçambicano como membro da Frelimo (Frente de Libertação de Moçambique), porém abandonou a trajetória ativista em função de discordâncias ideológicas com o movimento, passando a dedicar-se exclusivamente à escrita e publicação de seus livros. Balada de amor ao vento, lançado em 1993, foi o primeiro romance publicado em Moçambique, alterando o cenário literário nacional por se tratar de uma produção em língua portuguesa escrita por uma mulher.

Por meio da análise das temáticas abordadas pela escritora, é possível verificar não apenas o apelo político, legitimado pela causa a que a autora esteve ligada, mas também uma preocupação indelével com o mapeamento cultural do país, desde tempos remotos até a contemporaneidade, conforme explica Laranjeiras (2013, p. 335):

[Chiziane] vai mais longe e precede a uma arqueologia da cultura (em uma linha próxima das posições pós-coloniais e da inquirição das subalternidades), ao rastrear as influências dos comportamentos e dos hábitos coloniais na formação das mentalidades assimiladas, como quando recorre ao passado colonial para explicar os sonhos desvairados de algumas mulheres e homens.

A escritora contempla uma variedade de enredos que abarca a diversidade cultural em momentos distintos da história moçambicana. A pluralidade de culturas na geografia de Moçambique, bem como as questões geográficas através da tônica da língua são assuntos recorrentes quando se trata da África lusófona, uma vez que ambos os temas permeiam sua história desde o período colonial até os dias atuais, especialmente no que se refere à escrita feminina da região.

[...] as vozes femininas são poucas nas literaturas africanas de língua portuguesa. As causas são as mais variadas, mas talvez pudéssemos avançar uma hipótese que aponta para a falta de visibilidade da produção escrita feminina, ou seja, essa produção existe - ainda que tímida - porém tem recebido pouca atenção da crítica especializada, o que leva muitas 
vezes ao seu silenciamento. Esse fato, aliado às difíceis condições de difusão do livro africano de língua portuguesa no circuito internacional e até mesmo no espaço lusófono, cria um desconhecimento do que hoje as mulheres têm escrito em África (MACEDO, MAQUÊA, 2007, p.74).

De acordo com as pesquisadoras Tania Macêdo e Vera Maquea (2007), Chiziane se destaca em um contexto no qual vozes masculinas são preponderantes, como Mia Couto e José Craveirinha. Em sua obra é possível constatar uma trajetória de reinvenção da temática do feminino através da intransitividade do contexto africano, díspar em si próprio, cuja história e tradição permanecem em constante peleja com a modernidade.

Em função de questões geográficas, pela proximidade do sul com a África do Sul e as fortes resistências do norte, a metrópole teve maior dificuldade em assumir um controle efetivo do país, uma vez que, desde o início, norte e sul se consolidaram como países diferentes, sendo impossível falar em um Moçambique como unidade nacional, havendo grupos étnicos diferentes, e muitas vezes inimigos, convivendo no mesmo território e sendo obrigados a partilhar, a partir da colonização, do novo sistema linguístico imposto.

\section{A DANÇA COMO RESGATE DE UMA TRADIÇÃO RECRIADA}

O enredo de Niketche gira em torno de Rami, narradora e protagonista do romance, e a partir de monólogos e diálogos a trama é tecida, especialmente em função da relação que estabelece com o marido e as outras esposas do casamento polígamo que passa a viver. Julieta, Luísa, Saly e Mauá são as quatro mulheres de Tony, com as quais Rami inicia um convívio a partir da descoberta das traições.

Por meio da caracterização da narradora-protagonista, verifica-se a construção de um eu feminino atrelado à nação moçambicana, que forjaria uma futura identidade social para a mulher de Moçambique. Já as relações entre os personagens marcam as diferenças geográficas e históricas que determinam a sociedade do país e, essencialmente, as diferenças entre norte e sul, representando Moçambique como uma diegese.

Diante desta realidade, em que grande parte da população feminina já estaria estabelecida nas condições de submissão de um sistema patriarcal, a inserção da língua portuguesa viria agravar tal situação. O aprendizado do português era limitado aos homens, e o analfabetismo, que já acometia a maior parte da população, se apresentava mais significativamente entre as mulheres moçambicanas. Paradoxalmente, observa-se que a própria questão da língua será a porta de libertação feminina, pois a dominação do idioma garante à mulher condições de atuar em âmbitos oficiais com segurança, bem como, no caso da própria autora Chiziane, de produzir uma literatura que se torne conhecida mundialmente, como foi o 
caso de Niketche, esgotado em menos de quinze dias em Portugal e, hoje, lido no Brasil e em outros países, não apenas em língua portuguesa, mas traduzido para o inglês, espanhol e italiano, alcançando uma recepção em nível mundial.

Esta questão de trajectória literária no feminino tem, assim, tanto a ver com o que escrevem as mulheres como com o modo de ler o que as mulheres escrevem, isto é, as estratégias de leitura instrumentalizadas pela categoria do gênero a fim de fazer do acto da leitura uma mediação contra a centralidade de um sujeito flexionado por um único gênero, o masculino. Na verdade, as estéticas actualizadas em tendências e correntes artísticas não têm apenas a ver com o processo de criação e os "produtos", mas constroem-se também a partir de estratégias de leitura (MATA, 2007, p.423).

A observação de Mata aborda a recepção dos textos femininos na África. É, também, consequência de uma aceitação exterior da literatura feita por mulheres neste continente, descentralizando o gênero masculino, tanto no que se refere ao produto de sua escrita quanto ao seu receptor, pois se trata de uma mulher falando sobre mulheres em uma língua que outrora lhes fora apenas objeto de dominação.

Mata (2013) defende que o passado colonial deixou fraturas que permaneceram soterradas durante o período de constituição discursiva da nação moçambicana, de modo que a escrita de Chiziane e a epopeia de suas personagens acabariam por suprir, através do discurso, as lacunas que cristalizaram a condição feminina no país.

Por isso não se pode dizer que as personagens femininas de Paulina Chiziane - que predominam - sejam meras marionetes: na verdade, trata-se de um percurso intelectual que as personagens empreendem (e com elas a leitora) em vista da desmistificação de imagens femininas convencionais que chegam, pela ação autorreflexiva, ao autorreconhecimento em um contexto em que a alteridade se transforma em outridade, com estatuto reconhecido, e a tradição surge como tempo de renovação cultural para a mulher em Moçambique (MATA, 2013, p. 157).

Tal reflexão sobre a condição histórica feminina, bem como a influência da língua na reinvenção da mulher moçambicana, agiram como pano de fundo em Niketche, voltando-se para um caminho através do qual a mulher percorrerá sua própria trajetória, por meio de seu corpo e sua dança.

O momento no qual a dança é inserida nos liames ficcionais do romance delimita o lugar que o feminino ocupa na narrativa, manifestando-se enquanto cenário indicativo da libertação da mulher e suas alteridades, bem como no protagonismo da personagem principal.

\section{- Niketche?}

- Uma dança nossa, dança macua - explica Mauá -, uma 
dança do amor, que as raparigas recém-iniciadas executam aos olhos do mundo, para afirmar: somos mulheres. Maduras como frutas. Estamos prontas para a vida! (CHIZIANE, 2004, p. 160).

Trata-se de uma dança tradicional nortenha, através da qual as mulheres seduzem seus homens, mas que, no romance, apresenta-se como uma performance subversiva de Rami e as demais esposas, na intenção de castigar o marido pela má-conduta com a qual se comporta nos casamentos. Na condição de ritual, a dança niketche evoca a presença do corpo como um todo, corpo-texto, corpo-sujeito e corpo-épico, convocando o rito a dar voz às cinco alteridades femininas que atuam no romance.

Observa-se que, ao lançar mão do resgate do corpo como instrumento de libertação, este se apresenta como agente da memória. Mais que isso, subscreve-a à tradição através deste corpo. Para Chiziane, bem como para a oralidade moçambicana, o corpo é, antes de tudo, a emancipação do poder colonial, como trata Antonacci (2013). Segundo esta autora, a historicidade do ser africano se manifesta mediante códigos distintos dos ocidentais, dentre eles o da dança. Seria, pois, outra maneira de se relacionar com a natureza, com os próprios seres humanos e consigo.

[...] memórias ancoradas em experiências dos que só têm no corpo e em suas formas de comunicação heranças de seus antepassados e marcas de suas histórias. Em contínuos desterros, sem construídas séries documentais, vivendo e transmitindo heranças em performances, recursos linguísticos e artísticos, povos africanos pluralizam nosso alcance de acervos históricos, monumentos e patrimônios audiovisuais, situando a necessária arqueologia de saberes orais, a ser enunciada e valorizada (ANTONACCI, 2013, p. 17).

Ao enfrentar o caminho de pensar corporalmente, a autonomia se configura como a revelação da libertação da mulher. A obra de Chiziane prevê, deste modo, uma atitude política em relação à condição feminina e à própria tradição moçambicana, uma vez que "a dança é o resultado normal da audição poética" (ZUMTHOR, 1985, p. 33). Na releitura de um tradicional rito cultural local, inicia-se um processo de reescrita da tradição do país pelas vias da mão feminina e da própria condição de subjetivação da mulher, deslocamento este que se dá através do corpo e da exploração de sua potencialidade poética, sendo o poético, para Zumthor, justamente aquilo que afeta o corpo e o faz vibrar.

Tem-se que as cinco alteridades femininas (Rami, Julieta, Luísa, Saly e Mauá) se aliam no movimento da dança e trazem, pela arte, a junção literatura e dança, leitura e tradição, na nova modelização feminina.

Conforme bem define Zumthor, o corpo e, junto com ele, a voz, se configura como a única maneira de o ser humano manifestar-se, sendo ele próprio também parte da poeticidade que emana da literatura. Nesse ínterim, convém salientar ainda que: 
Com efeito, essa inscrição literária do corpo feminino, que, na sociedade moderna/tradicional, é lugar de múltiplas manipulações sociais, enquanto objeto de troca ou de ganho, marcado ou amputado, torna-se um lugar temático importante na atual escrita das mulheres africanas (LEITE, 2013, p. 28).

Enquanto eixo temático, o artifício da dança aproxima também o leitor da história contada por Chiziane. Ao lançar mão da dança, mais que envolvê-lo na trama, a autora produz uma cadeia de sentimentos e sensações que induzem o espectador/leitor a buscar - por meio do espetáculo e sob a égide do sensível - a cadeia de significados que seu movimento carrega.

A dança é a metáfora da relação poligâmica de Tony [...]. A hermenêutica desse texto vai propiciar uma viagem fundadora de sentidos. Se a realidade é um texto, como diria Michel Buttor, as manifestações humanas são textos passíveis de ser lidos (LOBO, 2006, p. 79).

As cinco alteridades femininas de Niketche experimentam a sensação de mesclar-se em uma apenas, o que seria a modelização de um novo eu feminino na cultura moçambicana, conduzida pela observação, olhar e percepção da narradora-personagem-protagonista, maestra da orquestra que este grupo entoa. A partir daí, verifica-se que a dança, na experiência sincrética entre cultura, política e arte, se manifesta como movimento espiral que enlaça os corpos e pode anunciar a condição feminina através da liberdade corporal.

Paulina Chiziane se vale de uma proposta rítmica que cadencia a linguagem da tradição oral mesclada ao enredo das personagens, criando um processo de verossimilhança no qual as mulheres são, também, filósofas e poetas de suas próprias histórias e de sua fala.

O poeta nigeriano Esiaba Irobi defende que, em África, a dança é a representante suprema da expressão artística, "arte por excelência" (IROBI, 2007, p. 900). Para ele, o ato de dançar atua para além da comunicação corporal, perfazendo um movimento sinestésico e, assim, agindo como o principal meio em que confluem o mundo exterior e interior, história e presente.

O corpo é o principal canal de expressão artística, seja ela uma pintura, uma dança, um livro como The black atlantic, esculpindo ou realizando. O meio é imaterial. A última fonte de significação é o corpo humano. É, portanto, uma vez que o corpo é o instrumento primário para incubação, articulação e expressão de todas as ideias, bem como transporte de toda arte, seja música, teatro, literatura, mensagens eletrônicas, festival ou carnaval, o que eu quero discutir é que é através da fenomenologia e alfabetização sinestésica (ou seja, o uso do meio do corpo como lugar de significação cultural) que cruciais aspectos do festival indígena Africano foram translocados para o Novo Mundo (IROBI, 2007, p. 900 - tradução nossa) $)^{3}$. 
A valorização da palavra impressa, em sociedades claramente orais, acaba por comprometer a compreensão do poder do corpo como “[...] um local de múltiplos discursos para esculpir a história, memória, identidade e cultura" (IROBI, 2007, p. 900) ${ }^{4}$. Desta forma, reforça que o conhecimento nestas sociedades, antes da escrita, fora vinculado através da inteligência do corpo humano, sendo ele o principal instrumento por meio do qual as manifestações, atualmente escritas, ocorriam.

Em se pensando as concepções teorizadas por Irobi, pode-se inferir que a condução dos atos de Rami e suas companheiras na história torna-se um retorno aos elementos íntimos da cultura moçambicana, em que pese as manifestações corporais que precederam a palavra. Neste sentido, a performance das esposas em movimento traz à tona valores autênticos oriundos da sociedade de onde vieram, expressando, pela matéria, o imaterial; e, pelo texto, o indizível.

Antonacci (2013) aborda a performance como manifestação concretizada e adensada de morfologia e simbologia, através da qual os corpos negros revelam seus aspectos culturais orais desfigurados por olhares coloniais. Assim, a apresentação performática da dança e seus movimentos que tomam todo o romance apresentam-se como gestos grávidos de sentidos, para que as palavras falem através dos atos do corpo-texto. Diante disso, as conversas da narradora com o espelho são, também, uma extensão dos seus limites corpóreos, como o solo de uma dança.

A representação do discurso de Rami consigo mesma, no momento em que são proferidas tanto suas palavras como também as palavras do espelho, traz esclarecimentos carregados de significações, através dos quais a protagonista baila sozinha a performance que sustentará sua libertação. Trata-se de instantes nos quais o âmago do sujeito se revela em um compêndio de sentidos, cuja linguagem lhe permite ultrapassar as barreiras sociais impostas. No caso de Rami, os obstáculos oriundos da tradição e da sociedade que não lhe permitem a fala e, por isso, ela dança.

- Por que danças tu, espelho meu?

- Celebro o amor e a vida. Danço sobre a vida e a morte. Danço sobre a tristeza e a solidão. Piso para o fundo da terra todos os males que me torturam. A dança liberta a mente das preocupações do momento. A dança é uma prece. $\mathrm{Na}$ dança celebro a vida enquanto aguardo a morte. Por que é que não danças? (CHIZIANE, 2004, p. 16).

A tomada de consciência é suscitada quando o espelho oferece a valorização da dança e dos gestos do corpo, convocando a protagonista a compartilhar este momento. Além disso, "A dança é uma prece., ou seja, é o ato que lhe permite aproximar-se do divino, mas que também será sua profanação em busca de um caminho pela libertação através do niketche.

Por sua vez, considerando o espelho como parte do pensamento da personagem, sua resposta sintetiza o caráter simbiótico que o texto assume com os movimentos da dança: 
Dançar. Dançar a derrota do meu adversário. Dançar na festa do meu aniversário. Dançar sobre a coragem do inimigo. Dançar no funeral do ente querido. Dançar à volta da fogueira na véspera do grande combate. Dançar é orar. Eu também quero dançar. A vida é uma grande dança (CHIZIANE, 2004, p. 16).

Nessa passagem da narrativa, quando Rami dança em frente ao espelho e, por isso, percebe a possibilidade de dialogar com ele, constata sua solidão e reage a ela por meio dos movimentos corpóreos, ao verbalizar: "É o meu silêncio que escuto. E o meu silêncio dança, fazendo dançar o meu ciúme, a minha solidão, a minha mágoa. A minha cabeça também entra na dança, sinto vertigens" (CHIZIANE, 2004, p. 16). A semente de libertação da protagonista dá sinais de eclosão no momento em que vê seu silêncio rompido por intermédio da dança, representação de sua voz.

\section{A PRÁTICA PERFORMÁTICA NA SUBVERSÃO DE UM RITUAL}

Há, no romance, uma dúbia relação que se estabelece com o feminino através do corpo da mulher, incorporado à sociedade moçambicana em duas distintas concepções, através da diferenciação cultural entre o norte e o sul do país ${ }^{5}$. Neste sentido, as associações se constroem por meio de sua ritualização, como é o caso dos ritos de passagem que ocorrem no norte, definindo a sacralidade de personagens como Mauá.

No entanto, a mistificação de tais ritos, por sua vez, estabelece relações de poder que cristalizam o papel da mulher na sociedade, conforme defende Rodrigues (1979):

As sociedades dispõem, contudo, de meios simbólicos de lidar com estas forças luminosas, canalizando-as, atenuando-as ou evitando-as. Nos ritos mágicos, por exemplo, o homem imagina que o controle que tem sobre as ideias permite-lhe exercer controle sobre as coisas. Van Gennep demonstrou que os ritos de passagem atuam como instrumentos de exercer controle simbólico sobre os perigos inerentes às fases de transição entre posições ou estados constituídos pela estrutura social (RODRIGUES, 1979, p. 18).

Verifica-se que a suposta liberdade sexual que tais rituais confeririam às mulheres do norte são relações de poder que se estabelecem entre homens e mulheres, pois, deste modo, determina-se o papel feminino na sociedade e cultura. Se, por um lado, a Rami é relegado o status de não mulher por não haver frequentado tais ritos e não gozar da liberdade sexual de personagens como Saly e Mauá, personagens nortenhas, por outro, o pensamento de Rodrigues contrapõe esta concepção ao defender que tais costumes não se configuram em liberdade para o corpo feminino, mas em instrumento de dominação e poder sobre ele, pois estratificam seu papel nestas sociedades. 
Ainda que a disparidade entre as duas regiões do país, aparentemente, se dê pelo argumento da liberdade que a mulher nortenha possui, esta não é senão uma liberdade ilusória, posto que está condicionada de maneira indelével a uma função sexual previamente determinada, aprisionando-a socialmente, a exemplo de Mauá, que afirma "Eu nem tenho estudos e não sei fazer nada" (CHIZIANE, 2004, p. 118).

O corpo ritualizado da mulher assume a simbologia da própria sociedade, pois expressa a unidade cultural em comunhão, sacralizando-se por meio de uma função predeterminada. Através desta realidade, Rami, Mauá e as outras esposas se igualam, pois suas expressões corpóreas simbolizam as sociedades das quais são originárias e que as aprisionaram.

Todavia, a tomada de consciência deste aprisionamento gera, em ambas as personagens, o questionamento de seu papel na sociedade, de modo que passam a estabelecer outra relação com seus corpos, profanando-os e revelando-os como instrumento de libertação, que se materializa no momento da transgressão por meio da dança niketche. As personagens encontram-se à margem da sociedade e seus discursos representam a cultura da qual emergiram. Entretanto, o movimento epifânico da dança representa a abertura de fissuras em seus conceitos e valores culturais e tais fendas agem como propiciadoras de mudanças significativas no modo de pensar-se e pensar o mundo. A epifania, que se apresenta através da dança, passa a corresponder a uma visão de mundo que ganha forma a partir da relação do eu com o corpo.

Dimen (1997) defende que em sociedades patriarcais a realidade feminina é, amiúde, uma experiência na qual mente e matéria (o corpo) são associadas e exploradas, de maneira que sua subjetividade possa ser subtraída, pois:

[...] o gênero denota uma estrutura de poder político, disfarçada em sistema de diferença natural. No patriarcado, o gênero é o modo pelo qual a consciência do ser e o consequente senso do próprio poder são mais imediatamente vivenciados (DIMEN, 1997, p. 46).

Podemos deduzir, através desta aferição, que o sistema patriarcal praticado em Moçambique define, a priori, a consciência que a mulher tem de si, determinando as relações de poder a serem estabelecidas, disfarçadas em diferenças naturais. Deste modo, o patriarcalismo relega o feminino a um papel secundário sem que, no entanto, haja, na mulher, a possibilidade ou o conhecimento para contestá-lo, pois "as mulheres podem perceber [...] que a sociedade as contrapõe aos homens como algo que é Outro, diferente. A cultura faz as mulheres tanto humanas como não humanas." (DIMEN, 1997, p. 46-47).

A percepção de que a condição feminina é algo cultural abre as portas para que a linguagem e, neste contexto, a literatura sejam campos frutíferos de exercício do poder político que o corpo feminino carrega. Por 
tratar-se do "outro", atribui-se a ele valores opostos ao masculino, tornando-o um campo oculto, corpo que se transfigura, em Niketche, em elemento de libertação.

George Vigarello (2000, p. 229) complementa a teoria do corpo como instrumento de autoconhecimento e autoafirmação ao afiançar que: "O corpo evoca numerosas imagens, sugere múltiplas possibilidades de conhecimento". Em certas situações, diz, "especialmente quando a relação com a escrita e com o livro não é geral, o corpo pode revelar uma profundidade social por vezes inimaginável”. Tem-se, então, que o corpo assume a função de pré-texto, através do qual se evoca o que posteriormente será explicitado.

A dança niketche provoca o surgimento de um discurso que se torna ato a partir da performance do corpo, de maneira que, sem ela, o texto em si se torna inválido e incoerente. Mais que isto, é o pilar por meio do qual se sustenta, num único ato, todo o romance, ou seja, confere-lhe o status de além-texto, pois sua significação transborda os limites da narrativa, a partir da qual a leitura assume também seus movimentos, ampliando a percepção do leitor para os significados que os gestos instituem através da escrita.

De acordo com Zumthor (1985, p. 83), “a voz, quando a percebemos, estabelece ou restabelece uma relação de alteridade, que funda a palavra do sujeito". Neste sentido, a vocalização da dança niketche, pela voz de Chiziane, estabelece uma relação de alteridade entre o romance e a mulher moçambicana. O sujeito-mulher, vocalizado pela narrativa da dança, vem, através dos movimentos do corpo, narrados e vocalizados por Rami, construir a relação de corpo-épico que dá à obra o caráter de libertação da mulher e do feminino na sociedade, sendo que as vias da voz eternizam o corpo, conferindo-lhe uma dimensão simbólica além dos limites físicos. A ação performática da dança no romance se vale do corpo para transfigurar a mudez à qual a mulher foi condicionada pelas vias da colonização e da sociedade patriarcal em que está inserida.

Desta forma, o discurso da mulher de Niketche se apresenta como resposta à tradição e à sua condição, ao apropriar-se de dois elementos que se configuraram como instrumentos de dominação: língua e corpo. Por conseguinte, a língua portuguesa, que segregaria a mulher africana e atuaria como mais um artifício para seu aprisionamento (a língua do colonizador), constitui-se, no romance, como meio através do qual constrói seu discurso libertário, apropriando-se de seu corpo de maneira que este se materialize, através da dança, como lugar poético de renovação, saindo da subserviência sem, no entanto, negar a tradição que compõe sua cultura.

Observa-se que a linguagem modela os discursos da narradora-protagonista Rami, cuja experiência de emancipação culmina em um final aberto, bem como permanece aberto o futuro da mulher moçambicana e do próprio país, conforme se caracteriza a maioria das obras pós-coloniais de Moçambique. 
No entanto, é necessário ressaltar que tal libertação se dá apenas no âmbito literário e do discurso, haja visto que:

[...] ele é literatura. É a literatura, livre e inorgânica, que é seu caminho. Por isso, menos que o ensinamento [...] ele é levado a conciliar com a necessidade social, representada frequentemente por convenções (pelos abusos), mas também pela razão. Somente a literatura poderia desnudar o jogo da transgressão da lei - sem o que a lei não teria fim - independentemente de uma ordem a cria. A literatura não pode assumir a tarefa de organizar a necessidade coletiva. [...] A literatura é mesmo, como a transgressão da lei moral, um perigo.

Sendo inorgânica, ela é irresponsável. Nada se apoia nela. Ela pode dizer tudo (BATAILLE, 1989, p. 22).

A aferição do pensador sintetiza o caráter ideológico e utópico que se verifica em Niketche, pois se entende, nesta análise, que o movimento de transgressão que o configura apenas é concebível por meio do texto.

A integração dos elementos que compõem a narrativa cria uma nova totalidade, que abarca o romance e transfere a ele a significação da emancipação do corpo feminino. Por este motivo, a associação da linguagem com o corpo e a dança recria o modelo da mulher moçambicana, de modo a viabilizar um movimento libertário ao mesmo tempo em que lhe permite o retorno à tradição.

\section{CONSIDERAÇÕES FINAIS}

A ficção em Niketche configura uma perspectiva de libertação para a mulher através da arte representada pela dança em leitura literária. A identidade cultural moçambicana é formada a partir de seus signos configurativos do passado, presente e futuro. É a tradição a serviço da modernidade, e esta, ao reescrever-se sob novos valores, transfere à mulher o papel de agente social ativo na inscrição legítima de sua própria história feminina.

Niketche é, portanto, o território ficcional do simbólico feminino moçambicano, representado pela dança que se manifesta por meio da língua portuguesa, instrumento de cultura, tradição e luta. Deste modo, a utopia da libertação da mulher apresenta-se, linguisticamente, através do gesto rumorejante do texto, colocando em evidência a subjetivação da mulher moçambicana e de seu corpo. É o seu corpo que se apropria, assim, da língua do colonizador e a ressignifica: torna-a sua. Este experimentar cria uma nova percepção de realidade uníssona, materializada pela dança recriadora, na paisagem de novas mensagens utópicas, no corpo e na voz da mulher moçambicana, conforme sintetiza esta última citação de Barthes (2012) da qual fazemos, também, nosso eco final:

Rumorejante, confiada ao significante por um movimento inaudito, desconhecido de nossos discursos racionais, nem por isso a língua deixaria um horizonte do sentido: o sen- 
tido, indiviso, impenetrável, inominável, seria no entanto posto longe como uma miragem, fazendo do exercício vocal uma paisagem dupla, munida de um "fundo"; mas em lugar de a música dos fonemas ser o "fundo" das nossas mensagens (como acontece na nossa Poesia), o sentido seria aqui o ponto de fuga do gozo [...] (BARTHES, 2012, p. 95).

\section{REFERÊNCIAS BIBLIOGRÁFICAS}

ANTONACCI, Maria Antonieta. Memórias ancoradas em corpos negros. São Paulo: EDUC, 2013.

BARTHES, Roland. O rumor da língua. São Paulo: Martins Fontes, 2012.

BATAILLE, Georges. O erotismo. Trad.: Antonio Carlos Viana. Porto Alegre: L\&PM, 1978.

CHIZIANE, Paulina. Niketche: uma história de poligamia. São Paulo: Companhia das letras, 2004.

DIMEN, Muriel. Poder, sexualidade e intimidade. In: BORDO, Susan; JAGGAR, Alison. Gênero, corpo, conhecimento. Trad.: Britta Lemos de Freitas. Rio de Janeiro: Record, 1997.

IROBI, Esiaba. What they came with: carnival and the persistence of African performance aesthetics in the diaspora. In: Journal of black studies. 2007. Disponível em: http://jbs.sagepub.com/content/37/6/896. Acesso em 26 mai. 2018.

LARANJEIRA, Pires. Chiziane: uma escrita impressiva no feminino. In: MIRANDA, Maria Geralda de; SECCO, Carmen Lucia Tindó. Paulina Chiziane: vozes e rostos femininos de Moçambique. Curitiba: Editora Appris, 2013.

LOBO, Almiro. Niketche, uma história de poligamia: a moçambicanidade revisitada. In: CHAVES, Rita; MACÊDO, Tania. Marcas da diferença: as literaturas africanas de língua portuguesa. São Paulo: Alameda, 2006.

MACÊDO, Tania; MAQUEA, Vera. Literatura de língua portuguesa: marcos e marcas - Moçambique. São Paulo: Arte \& Ciência, 2007.

MATA, Inocência. Paulina Chiziane e a exposição de um "ossário de interioridades mortais”. In: MIRANDA, Maria Geralda de; SECCO, Carmen Lucia Tindó. Paulina Chiziane: vozes e rostos femininos de Moçambique. Curitiba: Editora Appris, 2013.

Mulheres de África no espaço da escrita: a inserção da mulher na sua diferença. In: CAVALCANTI, Laura; MATA, Inocência. A mulher em África: vozes de uma margem sempre presente. Lisboa: Edições Colibri, 2007. 
RODRIGUES, José Carlos. Tabu do corpo. Rio de Janeiro: Achiame, 1979.

VIGARELLO, Georges. O corpo inscrito na história: imagens de um “arquivo vivo". Projeto história. São Paulo. v. 21, novembro/2000.

ZUMTHOR, Paul. A letra e a voz: a literatura medieval. São Paulo: Companhia das letras, 1993.

. Performance, recepção, leitura. Trad.: Jerusa Pires Ferreira; Suely Fenerich. São Paulo: Cosac Naify, 1985.

Recebido para publicação em 31/05/2018

Aprovado em 25/09/2018

\section{NOTAS}

1 Doutoranda e mestre pela PUC - SP, Programa de Estudos Pós-Graduados em Literatura e Crítica Literária. E-mail revshimbo@gmail.com

2 Para fins de esclarecimento, o nome do romance será grafado como Niketche (letra maiúscula), sendo as alusões à dança escritas como niketche (letra minúscula).

3 The body is the major conduit of artistic expression, whether is the painting, a dance, a book like The Black Atlantic, sculpting, or performing. The medium is immaterial. The ultimate source of signification is the human body. It is therefore because the body is the primary instrument for incubating, articulating, and expressing all ideas as well as transporting all art, be it music, drama, literature, electronic messages, theater, festival, or carnival, that I want to argue that it is through phenomenology and kinaesthetic literacy (i. e., the use of medium of the body as a site of cultural signification) that crucial aspects of indigenous African festival theater were translocated to the New Word.

$4[\ldots]$ a site of multiple discourses for sculpting history, memory, identity, and culture.

5 Tanto o processo de colonização quanto o período de guerras posterior a ele acentuaram as diferenças regionais existentes entre norte e sul do país, sendo o norte caracterizado por uma sociedade tradicional, em que prevalecem os costumes oriundos das culturas bantus, e o sul marcado pelo desenvolvimento econômico-social, em especial em função da aproximação com a África do Sul. 